Centro Universitário de Brasília - UniCEUB Faculdade de Ciências da Educação e Saúde - FACES

Programa de Iniciação Científica - PIC

\title{
REPRESENTAÇÕES DE MULHERES NO CONTEXTO DE CONSTRUÇÃO DA NOVA CAPITAL, BRASÍLIA
} (1956-1961)

\author{
Estudante Bolsista: José Gomes do Nascimento \\ Estudante Voluntária: Larissa Brunnon Querino de Almeida \\ Estudante Colaboradora: Anna Lorena Morais Silva
}


Centro Universitário de Brasília - UniCEUB Faculdade de Ciências da Educação e Saúde - FACES Programa de Iniciação Científica - PIC

\section{REPRESENTAÇÕES DE MULHERES NO CONTEXTO DE CONSTRUÇÃO DA NOVA CAPITAL, BRASÍLIA (1956-1961)}

Relatório final apresentado à Assessoria de Pós-Graduação e pesquisa pela Faculdade de Ciências da Educação e Saúde - FACES

Estudante Bolsista: José Gomes do Nascimento Estudante Voluntária: Larissa Brunnon Querino de Almeida Estudante Colaboradora: Anna Lorena Morais Silva

Orientação: Prof. Dra. Cristiane de Assis Portela 


\section{REPRESENTAÇÕES DE MULHERES NO CONTEXTO DE CONSTRUÇÃO DA NOVA CAPITAL, BRASÍLIA (1956-1960) ${ }^{1}$}

Resumo: O projeto faz parte de uma pesquisa mais ampla, que busca analisar representações construídas por e sobre mulheres durante o período da construção de Brasília. Nesta etapa foi realizado o mapeamento de fontes documentais que auxiliassem o cotejamento de dados acerca do tema. A princípio, o escopo da pesquisa consistiu em um conjunto documental diversificado: a) ocorrências policiais; b) registros de óbitos; c) carteiras de trabalho de mulheres; e d) recortes de jornais. As ocorrências policiais foram consideradas a documentação mais relevante para essa etapa de pesquisa, sendo também aquela que contém o maior volume documental: são 10 livros-ata que registram 3.971 ocorrências de crimes ocorridos entre os anos de 1957 e 1961, o que torna possível mapear as situações de violência às quais as mulheres estiveram submetidas no contexto da construção. Nesse mapeamento foram identificadas 279 situações de crimes cometidos contra mulheres, constantes em 236 registros de ocorrências, sendo em sua maioria denúncias feitas pelas próprias vítimas. Um número bem maior apresenta mulheres na condição de envolvidas, seja como denunciantes de violências cometidas contra outras pessoas, seja quando listadas como testemunhas ou nos casos em que são acusadas de algum crime. A fim de qualificar essas formas de violência, foram utilizadas as tipificações estabelecidas pela Lei Maria da Penha (91 registros de violência em âmbito doméstico) e 145 registros de violências classificados de acordo com Código Penal (crimes contra a pessoa e a vida que não denominam especificamente a esfera familiar e doméstica). Há de se ressaltar que as denúncias de violências contra mulheres - naquele período bem como nos dias de hoje - se caracterizam por serem crimes sub-notificados, visto que estão inscritos

\footnotetext{
${ }^{1}$ Cristiane de Assis Portela- Doutora em História e orientadora do projeto. E-mail: cristiane.portela@uniceub.br / José Gomes do Nascimento (Bolsista) e Larissa Brunnon Querino de Almeida (Voluntária) - Estudantes de Graduação em História/ Anna Lorena Morais Silva (Colaboradora)- Estudante do Curso de Especialização em História, Sociedade e Cidadania do UniCEUB.
} 
em uma cultura patriarcal e machista que desestimula, sobretudo, as denúncias de violências que ocorrem em âmbito doméstico e àquelas que se referem a crimes sexuais. Assim, interessou mais compreender os tipos de crimes cometidos e denunciados do que identificar um percentual representativo das violências às quais às mulheres estiveram expostas naquele momento. Entre os 91 casos de violência doméstica predominam a violência física (42) e a violência psicológica (29), seguidas da violência patrimonial (13) e violência moral (07). Não houve registros de violência sexual em espaços privados. Dentre os demais crimes identificados, 145 registros, predominam: lesão corporal (42); estupro/ tentativa de estupro (40) e assédio de tipo sexual (15), em que se destacam crianças como vítimas. A esses se somam os casos de roubos/furtos (13) e homicídio/ tentativa de homicídio (08). Em seguida, denúncias de injúria/calúnia/difamação (05), assédio moral/constrangimento ilegal (04), subtração de incapazes (06) e outros totalizam 52 ocorrências. Apesar de numericamente pouco expressivas e pela dificuldade de tipificação de acordo com a classificação adotada, as denúncias de prostituição, de tentativas de suicídio e de curandeirismo indicam elementos significativos para a compreensão das representações que envolvem mulheres naquele contexto. O panorama apresentado fornece um referencial muito significativo para o desdobramento de pesquisas, bem como, a possibilidade de pensar transformações e permanências em relação à situação histórica de violência contra mulheres no Brasil.

Palavras-chave: Construção de Brasília. Violência contra Mulheres. Ocorrências Policiais. 
SUMÁRIO

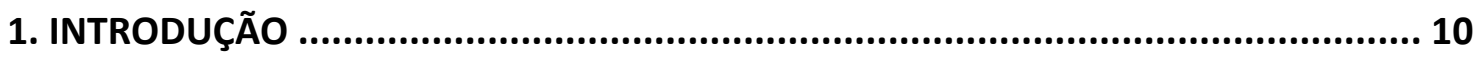

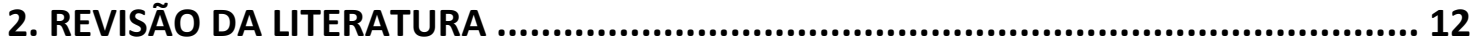

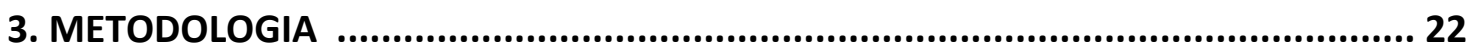

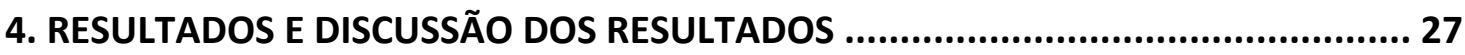

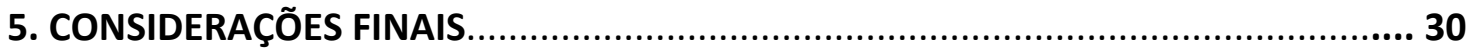

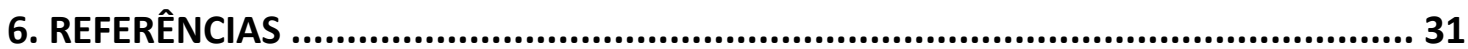




\section{INTRODUÇÃO}

Ainda que maioria numérica no conjunto populacional brasileiro e a despeito da incontestável conquista de espaços sociais nas últimas décadas, mulheres fazem parte dos sujeitos que historicamente vivenciaram processos diversos de exclusão social. Mesmo em face desse processo de exclusão, criaram e recriaram elementos culturais, lutaram por conquistas e engendraram relações de equidade mesmo em cotidianos adversos. Ainda há muito que conquistar e assim, mulheres continuam lançando horizontes de expectativas quanto às possibilidades de se construir representações que restituam o protagonismo feminino na história do Brasil. Nesse sentido, o objetivo desta pesquisa foi analisar representações construídas por e sobre mulheres durante o período da construção de Brasília, entre os anos de 1956 e 1960.

Conforme Jatahy Pesavento (2005), se a História trabalha com a mudança no tempo, logo podemos concluir que o que se entende por "mulher", "mulheres" e "gênero" também se resinificou no decorrer dos tempos, nossa tarefa nesse sentido seria resgatar os sentidos conferidos a essas palavras ao longo de toda uma historiografia, que durante muito tempo invisibilizou e renegou espaços - sob práticas e discursos silenciantes - a essas mulheres à participação como sujeitos de direito na história.

Falar e escrever sobre mulher na história, significa dar visibilidade e reparar parte de uma exclusão a nós alcunhadas, pois uma vez que, tentar dotar de presença traços femininos em uma conjuntura e historiografia que sempre teve domínio reservados essencialmente aos homens é uma tarefa bastante difícil. Porém, mais que reparar essa exclusão, nossa tarefa é buscar formas mais eficientes de fornecer legitimidade ao que se entende a respeito da História das mulheres e das relações de gênero. Pois a história não pode ser apenas uma tentativa de corrigir registro incompleto do passado, mas se torna um modo de compreender criticamente como a história opera enquanto lugar de produção do saber de gênero.

O conhecimento histórico na perspectiva da História Cultural ampliou - e ainda está, com a chamada Nova História Cultural - o conceito de fontes em diversos estudos, passando a enfatizar e a utilizar em larga escala as representações na construção do conhecimento, sendo assim, esta pesquisa focalizou em estudos que 
contribuíssem e reforçassem os estudos para uma problemática que deve ser feito referente à inclusão das mulheres e conceito de gênero como categoria analítica da história de Brasília. Há de se ressaltar que desde muito se tornou hegemônica uma narrativa histórica pautada no projeto modernista empreendido por Juscelino Kubitschek- JK para transferência da capital. Tal narrativa enfatizou a construção de Brasília como símbolo da modernidade e de um período de amenidade dos conflitos políticos no país. Consolidou-se com isso uma historiografia centrada na identificação de marcos fundantes e a valorização dos personagens a estes associados. Tais personagens compõem um panteão de heróis estritamente masculino: além de JK, Oscar Niemayer, Lúcio Costa, Ernesto Silva, Israel Pinheiro, Bernardo Sayão, entre outros. Tais percepções críticas estão evidenciadas nas obras que compõem um panorama de produções sobre a história de Brasília e com as quais estabelecemos interlocução: Sousa (1983; 2007), Holston (1993; 2013), Beú (2012), Ribeiro (2008) e Oliveira (2005).

Nesta etapa da pesquisa foi realizado o mapeamento de fontes documentais que auxiliassem o cotejamento de dados acerca do tema. A princípio, o escopo da pesquisa consistiu em um conjunto documental diversificado: a) ocorrências policiais; b) registros de óbitos; c) carteiras de trabalho de mulheres; e d) recortes de jornais. As ocorrências policiais foram consideradas a documentação mais relevante para essa etapa de pesquisa, sendo também aquela que contém o maior volume documental: são 10 livros-ata que registram 3.971 ocorrências de crimes ocorridos entre os anos de 1957 e 1961, o que torna possível mapear as situações de violência às quais as mulheres estiveram submetidas no contexto da construção. Nesse mapeamento foram identificadas 279 situações de crimes cometidos contra mulheres, sendo em sua maioria denúncias feitas pelas próprias vítimas. Percebemos nesse material uma correlação muito interessante entre as tipificações de violências definidas pela Lei Maria da Penha (Lei 11.340/2006) e os casos relatados por mulheres, reafirmando-se para nós, a possibilidade de pensar transformações e permanências em relação à situação histórica de violência contra mulheres.

Todas as fontes utilizadas na pesquisa fazem parte do acervo histórico do Arquivo Público do Distrito Federal- ArPDF, estando esses documentos disponíveis em versão digitalizada (mas ainda não disponibilizada on line). O acervo do ArPDF é 
composto por material textual (registros funcionais e de despesas, livros de atas e ocorrências, decretos, recortes de jornais, dentre outros), plantas arquitetônicas, fotografias, filmes, folhetos, cartazes, periódicos e material bibliográfico; compondo um cenário de relevância sem igual para pesquisas sobre a história de Brasília e do Distrito Federal.

Compreendido o contexto histórico da análise, procedemos à análise dos discursos produzidos, utilizando principalmente as ocorrências policiais, identificando por meio de uma tabela de análise documental: tipificações de ocorrências, datas, localidades, expressões recorrentes e particularidades que auxiliaram no agrupamento as ocorrências por meio de aspectos comuns quanto as tipificações, conferindo assim, coesão ao material a ser trabalhado.

A historiografia do gênero feminino foi inscrita sob um emaranhado de processos violentos de submissão, repressões e esquecimento. Porém, mais do que reparar essa exclusão, nossa tarefa é buscar formas mais eficientes de fornecer legitimidade ao que se entende de história das mulheres e das relações de gênero. Pois a história não pode ser apenas uma tentativa de corrigir registro incompleto do passado, mas uma forma de compreender criticamente como a história opera enquanto lugar de produção do saber de gênero.

A concepção histórica que norteia essa perspectiva inseriu Brasília como o centro demarcador de um novo contexto histórico para a nação. Entretanto, compreendemos que o momento histórico que hoje vivenciamos exige que novas perspectivas se apresentem, orientando a produção de uma história pública perpassada por outros vieses. Permite-se assim reconhecer as diferenças e as hierarquias de gênero, refletindo sobre os direitos que asseguram condições de igualdade aos sujeitos sociais e estabelecem correlações entre as temporalidades históricas.

\section{REVISÃO DA LITERATURA}

É quase impossível falar de mulheres sem falar de gênero, no entanto, devemos estar atentos para que este último conceito não seja concebido como restrito a uma análise de mulheres. Conforme Joan Scott (1995), o termo foi um empréstimo feito à 
gramática; em seu sentido original, gênero é o fenômeno da presença para designar indivíduos de sexos diferentes ou ainda coisas sexuadas. De acordo com a estudiosa, o conceito, nas ciências sociais, tomará outra conotação a distinção entre atributos culturais alocados a cada um dos sexos e a dimensão biológica dos seres humanos. $\mathrm{O}$ grande impacto que vem produzindo nas análises sociais consiste no fato de que uma parte da humanidade estava na invisibilidade - as mulheres - e seu uso assinala que, tanto elas quanto os homens são produto do meio social, e, portanto, sua condição é variável. Assim, gênero consiste num caráter fundamentalmente social, cultural, das distinções baseadas no sexo, afastando o fantasma da naturalização.

Isso está de acordo com o que foi citado por Guacira Lopes Louro (1996), já que para ele, gênero veio contrapor-se ao conceito de sexo. Se este último se refere às diferenças biológicas entre homem e mulher, o primeiro diz respeito à construção social e histórica do ser masculino e do ser feminino, ou seja, às características e papéis atribuídos a cada um deles na sociedade. O que quer dizer que agir e sentir-se como homem e como mulher depende de cada contexto sociocultural.

A exemplo disso, Rachel Soihet (2012) descreve no texto Mulheres pobres $e$ violência no Brasil sobre a importância da defesa da honra. O período que vai do final do século XIX até a primeira metade do XX - onde o Brasil e principalmente o Rio de Janeiro (capital) passava por modificações sociais e estruturais - foi marcado por um contexto em que a "honra" ${ }^{2}$ da mulher era o que dava legitimidade ao papel do homem como dominador, uma concepção que impôs ao gênero feminino desconhecimento de si, do seu corpo, criando práticas de repressão da sua própria sexualidade, práticas essas reforçadas para atender um sistema de dominação familiar e social; que ditava, de forma repressiva o que era e o que não era permitido e as maneira punitiva quais seriam as consequências de não se manter a honra. Logo, as mulheres eram divididas em duas categorias: 'ser virgem e ser mãe' num contexto em que, a imagem da Vigem Maria era o ideal de pureza a ser seguido; e entre aquelas 'mães putas', mulheres que se deixavam desvirginar, que tendo filhos ilegítimos teriam que arcar com os próprios erros, essas mais propensas a sofrerem violências físicas e violências morais, caracterizadas pela exclusão e preconceitos. Por conseguinte, fica

\footnotetext{
${ }^{2}$ O que Carla Pinsky (2012) no texto Mulheres nos anos Dourados, descrevendo os anos dourados, a partir de jornais da década de 1950, vai chamar de 'virtudes'.
} 
explícito o enorme paradoxo quando pensamos na "honra" dessas mulheres levando em consideração as oportunidades e a classe em que estavam inseridas na sociedade, pois,

(...) as formas de violências específicas da condição feminina, aquela relativa ao relacionamento homem/mulher revestia-se de caráter especial. Apesar da existência de muitas semelhanças entre mulheres de classes sociais diferentes, aquelas das camadas populares possuíam características próprias, padrões específicos, ligados ás suas condições concretas de existência. Como era grande sua participação no "mundo do trabalho", embora mantidas numa posição subalterna, as mulheres populares, em grande parte, não se adaptavam às características dadas como universais ao sexo feminino: submissão, delicadeza, fragilidade. (SOIHET, 2012, p. 366 , grifo da autora).

Essas mulheres trabalhavam muito, e um 'pequeno' detalhe dificultava mais ainda as suas vidas na época: a maioria não era formalmente casadas. Elas brigavam na rua, pronunciavam palavrões; assim fugiam totalmente da regra estereotipada do período que atribuía à mulher o rótulo de sexo frágil. Dado que, elas não brigavam apenas na rua, a grande maioria dessa mulheres populares, não aguentava calada a autoridade familiar que o homem dispunha, sofrendo dessa forma, com a violência do seu marido toda vez que ele era acometido de insegurança quanto ao papel do homem naquela sociedade, pois ela não era submissa igual as que possuíam "honra", gerando no "homem macho" uma demonstração de fraqueza e impotência.

Essa explicação se completa pelo fato de que a tais homens, desprovidos de poder e de autoridade no espaço público - no trabalho e na política -, seria assegurado o exercício no espaço privado, ou seja, na casa e sobre a família. Nesse sentido, qualquer ameaça à sua autoridade na família lhes provocava 
forte reação ${ }^{3}$, pois perdiam os substitutos compensatórios para sua falta de poder no espaço mais amplo. (SOIHET, 2012, p. 366).

Vale ressaltar que a maioria dessas construções foram reforçadas e mantidas sobre práticas e discursos também ao longo de todo o século $X X$, em que se a categoria "mulher" foi dividida, conforme Carla Pinsky (2012), - período conhecido como "anos dourados" na década de 1950 - entre a "moça de família" e "moça leviana". As primeiras corresponderiam a possibilidade de um casamento modelo, a uma vida de dona, cuidadora do lar e de seus filhos, sendo moças que se portavam corretamente e evitavam a todo custo serem mal faladas. As levianas eram pelo contrário, eram vistas como as moças que deviam ser evitadas a todo custo; moças com que os homens apenas se divertiriam, mas não se casariam, pois segundo o código de moralidade dominante de família da época, a mulher teria que possuir "virtudes", tais como: ser recatada (bela e do lar), dócil, obediente e submissa aos caprichos do seu marido.

Segundo Pinsky (2012, p. 613) "A moral sexual dominante nos anos 50 exigia das mulheres solteiras a virtude, muitas vezes confundida por ignorância sexual e sempre, relacionadas à contestação sexual e à virgindade." Porém muitas dessas mulheres tiveram a vontade e coragem de transgredir, e conseguiram com sucesso, outras foram estigmatizadas, discriminadas e abandonadas como aponta o trecho abaixo:

\begin{abstract}
"Algumas conseguiram escapar à pecha de leviana ou mal falada. Mesmo ousando em termos de sexualidade, mantiveram as aparências de moças respeitáveis. Algumas dessas "rebeldes" foram felizes nos seus amores. Outras, não tiveram tanto sucesso e sofreram - estigmatizadas,
\end{abstract}

\footnotetext{
${ }^{3}$ Conforme Rachel Soihet (2012), essa forte reação ocorria pelo fato de que esses homens mais pobres estavam longe de poder assumir o papel mantenedor do tipo de família previsto pela ideologia dominante na época, tão pouco o dominar, por conta do tipo de mulher citado acima. Ou seja, ele não conseguia desempenhar o papel que a sociedade exigia nem mesmo no seu âmbito privado.
} 
discriminadas ou até abandonadas - as consequências de seus comportamentos desviantes e, inconsequentes, indevidos ou ilícitos". (PINSKY, 2012, p. 613, grifos do autor).

A categoria de análise de gênero enfrentou ao longo da historiografia uma trajetória bastante difícil. Nas ciências humanas, como escreve Rachel Soihet (2007, p. 284) a disciplina de História foi a que mais tardiamente apropriou-se dessa categoria, assim como da própria inclusão de "mulher" ou de "mulheres" como categoria analítica na pesquisa histórica. Devido a falsa percepção de que, "ao falar dos homens, as mulheres estariam sendo, igualmente, contempladas; o que não correspondia à realidade. Mas, também, não eram todos os homens que estavam representados nesse termo: via de regra, era o homem branco ocidental". (SOIHET; PEDRO, 2007, p. 284).

De acordo Joan Scott (1995),, a partir dos anos de 1960, com o desenvolvimento de novos campos tais como a história das mentalidades e a história cultural, ocorre um avanço na abordagem das questões do feminino. Constituída a História das Mulheres nesse momento, ainda existia um descrédito das correntes historiográficas polarizadas para um sujeito humano universal.

"(...) mesmo ficando em aberto a maneira como o "sujeito" é construído, a teoria tende a universalizar as categorias e a relação entre o masculino e o feminino. A consequência para os (as) historiadores (as) é uma leitura redutora dos dados do passado. Mesmo se esta teoria leva em consideração as relações sociais, relacionando a castração com a proibição e a lei, ela não permite a introdução de uma noção de especificidade e de variabilidade históricas". (SCOTT, 1995, p. 16).

Assim para a autora, gira em torno dos esforços no sentido de acomodar dentro dessa historiografia as mulheres numa história que, de fato, as excluía, constata-se fatal essa contradição instaurada. Pois a história das mulheres, com toda 
sua quantidade de dados, com suas afirmações de que as periodizações tradicionais não funcionavam quando as mulheres eram levadas em conta, com sua evidência de que as mulheres influenciavam os acontecimentos e tomavam parte na vida pública, com sua insistência de que a vida privada tinha uma dimensão pública; implicava segundo a autora, a negação de que o sujeito da história se constituía numa figura universal. A crítica levantada por Joan Scott gira em torno de que categoria 'mulher', que constituía uma identidade diferenciada da de 'homem', não seria suficiente para explicá-las.

Assim, com vistas à explicação do conceito de gênero e de como as relações entre os sexos estruturaram-se ao longo da história, o conceito possui uma dualidade: de um lado, o gênero é um elemento constitutivo de relações sociais baseado nas diferenças percebidas entre os sexos; de outro lado, o gênero é uma forma primeira de significar as relações de poder. Esta última, propõe que a história seja escrita "a respeito de como os significados subjetivos e coletivos de homens e mulheres, como categorias de identidade, foram construídos" (SCOTT, 1995, p. 3). Trata-se de observar os significados variáveis e contraditórios que são atribuídos à diferença sexual.

No entendimento de Simone de Beauvoir (1960, p. 129), talvez o problema esteja no fato de que "O homem é definido como ser humano e a mulher é definida como fêmea. Quando ela se comporta como um ser humano, ela é acusada de imitar o macho". E é dentro de toda uma conjuntura e historiografia, machista, opressora e silenciante que urge a necessidade de temas como esses serem cada vez mais discutidos, afim de rompermos, não apenas com as desigualdades conferida às mulheres, como também, de entendermos essas hierarquias; como homens e mulheres - como categorias de identidade - foram construídas, mantidas e resignados ao longo da história. Nesse sentido, os estudos acerca da problemática de gênero e práticas culturais têm contribuído para a profundidade teórica reflexiva, possibilitando entender as representações conferidas às mulheres na construção de Brasília, mediante seus relacionamentos, estilos de vida e dificuldades - por serem do sexo feminino - em uma determinada época e espaço.

Nessa perspectiva Joelma Rodrigues da Silva (1995) demostra no seu trabalho sobre a prostituição feminina em Brasília no período de 1957 a 1961, que as mulheres tiveram uma participação histórica no período da construção da cidade. 
Principalmente por meio de ocorrências policiais, a autora apresenta um lado ocultado na história oficial de Brasília, demonstra não apenas que a prostituição era latente na capital, mas também que ela permaneceu em zonas de Baixo Meretrício até meados de 1961. A partir de outras fontes, como: fontes orais de homens, mulheres, da medicina, da igreja e da polícia; a autora apresenta um conjunto de representações a respeito da mulher e do cotidiano nas relações de gênero no período proposto, abordando todo o preconceito presente na época e também as violências sofridas por essas prostitutas.

A abordagem de gênero possibilitou a discussão das relações de poder entre homens e mulheres e explicitou a construção da desigualdade de condições na história das sociedades ocidentais. Hoje, o rompimento da dicotomia que destinava aos homens o domínio dos espaços públicos e às mulheres o domínio do âmbito doméstico, não esgotou a necessidade de se discutir as relações de gênero, já que as relações de poder são inerentes a elas e todas as relações sociais sofrem transformações constantes e contínuas ao longo da história, configurando sempre novas representações.

Para Ricoeur (1977, p. 56), a interpretação é a criação de um texto, fundado na relação com o mundo, que não é apreendido diretamente, mas inferido a partir do que é dito sobre ele, através de discursos que constituem representações. Nessa mesma perspectiva, Pierre Bourdieu (2000) destaca a importância do discurso performativo (que objetiva na prática aquilo que se diz), lembrando que a eficácia do discurso depende da autoridade daquele que o anuncia: "o poder sobre o grupo que se trata de trazer à existência enquanto grupo é, a um tempo, um poder de fazer o grupo impondo-lhe princípios de visão e di-visão comuns, portanto, uma visão única da sua identidade, e uma visão idêntica da sua unidade". (BOURDIEU, 2000: p. 117). Pensado dessa maneira, os discursos (e as representações constituídas por eles) estão intrinsecamente ligados à identidade, já que essa é constituída em meio a relações sociais de poder através de uma incessante negociação entre a construção de um "eu" e um "nós". 
Para Orlandi (2005), o discurso é a representação histórica do imaginário de quem o elabora, materializando sempre uma ideologia ${ }^{4}$ que não se restringe àquele que a profere, mas a uma memória coletiva que contém vários indivíduos. A importância da interpretação da Análise do Discurso - teoria da autora - está na ressignificação da noção de ideologia, pois interpretar trata-se de uma noção discursiva do conceito. Para ela, “[...] não há sentido sem interpretação e, além disso, diante de qualquer objeto simbólico o homem é levado a interpretar". (ORLANDI, 2005, p. 45). Das ferramentas da Análise do Discurso, algumas noções são fundamentais para a análise das nossas fontes - principalmente para as ocorrências policiais e os livros de óbito -, são elas: A condição de produção desses discursos, ou seja, o contexto imediato da produção dos documentos; e o interdiscurso, que seria o já-dito, pois ele é um conjunto de formulações feitas e já esquecidas. Contudo, não podemos esquecer o não dito, isto é, o implícito do discurso. Devemos nos atentar para a relação da linguagem com a falta, o equívoco; em outras palavras, coloca-se em questão a incompletude do discurso, uma vez que toda linguagem é incompleta, pois nem os sujeitos, os discursos e muito menos os sentidos são prontos e acabados, visto que "[...] há uma dimensão do silêncio que remete ao caráter de incompletude da linguagem: todo dizer é uma relação fundamental com o não dizer". (ORLANDI, 1992, p. 12).

Indo ao encontro com as perspectivas recentes dos "estudos culturais", o sociólogo português Mendes (2002) considera que a identidade é um conceito crucial porque funciona como ponto de ligação entre os discursos e as práticas. Por um lado, estes procuram colocar-nos em um lugar enquanto sujeitos sociais de discursos particulares e, por outro, os processos produtores da subjetividade nos constroem como sujeitos que podem falar e ser falados. Dessa maneira concebemos a análise das representações construídas sobre mulheres. Entende-se assim, que as identidades são múltiplas e relacionais, construídas na diferença, além de situacionais e históricas,

\footnotetext{
4 “Há vários significados para o termo. Um dos mais abrangentes apresenta a ideologia como um sistema de 'ideias' ou, mais exatamente, de crenças mais ou menos coerente. Silva (2013), considera que as ideologias são formas de se entender o mundo e de se posicionar nele. Essa definição, porém, não é a única. [...]De qualquer modo, existe o consenso de que nenhuma sociedade é desprovida de crenças ou valores e a ideologia é parte desse sistema de valores mais amplos". - SILVA, K.V. SILVA. M. H. Dicionário de conceitos históricos. 3.ed., São Paulo: Contexto, 2013, p. 205.
} 
estando em constante reelaboração. Assim o autor considera que as identidades se constroem no e também pelo discurso, em lugares históricos e institucionais específicos, em formações prático-discursivas específicas e por estratégias enunciativas precisas. Montenegro $(1993$, p. 56) ressalva que a memória é resultante de vivências individuais e também da maneira com a qual se interioriza os significados dessas experiências, possibilitando "resgatar as marcas de como foram vividos, sentidos, compreendidos determinados momentos, determinados acontecimentos; ou mesmo o que e como foi transmitido e registrado pela memória individual ou coletiva".

Em conformidade com essas compreensões, vislumbramos um triplo desdobramento: a) a contribuição para a formação cidadã da população do Distrito Federal, estimulando o sentimento de pertencimento às mulheres por meio da construção de uma história pública sobre a presença feminina, perpassando os conceitos de memória/ história/ identidade; b) a ampliação dos cenários de produção acadêmica acerca da história do Distrito Federal, ao apresentar novas possibilidades de utilização de fontes documentais, incitando releituras das narrativas produzidas até o momento; e c) o estímulo à utilização de fontes documentais no ensino de História do DF.

A expectativa desta pesquisa é a de que possamos corroborar com a produção de uma história pública perpassada por outros vieses, que considerem as narrativas produzidas por diferentes sujeitos. Por ser uma definição que comporta diferentes apreensões, nos alinhamos com uma perspectiva que compreende história pública como "uma possibilidade não apenas de conservação e divulgação da história, mas de construção de um conhecimento pluridisciplinar atento aos processos sociais, às suas mudanças e tensões. Num esforço colaborativo, ela pode valorizar o passado para além da academia; pode democratizar a história sem perder a seriedade ou o poder de análise". (ALMEIDA; ROVAI, 2011, p. 59). É notório que conceito de história pública não é novo, mas a reflexão sobre sua importância na academia vem se expandindo. Destarte, não se trata da eliminação da ciência histórica para a emergência da história pública, e sim das reflexões sobre a atuação do profissional capaz de estimular a consciência histórica para um público amplo, não acadêmico. 
Consideramos relevante a possibilidade de visibilizar a emergência de situações históricas negligenciadas nas narrativas tornadas hegemônicas, aquelas que nos ensinaram a perceber a história de Brasília sob uma ótica restrita, que compreende Brasília "capital do país", como uma realidade una e centrada em seu Plano Piloto, este, por sua vez um lugar social também tornado hegemônico em detrimento das demais comunidades do Distrito Federal. Do ponto de vista do saber escolar, podemos afirmar que qualquer perspectiva que seja excludente fere a possibilidade de construção de conhecimentos significativos. Desta maneira, por meio da valorização das narrativas produzidas por atores envolvidos no cotidiano das comunidades, tornase possível problematizar os elementos construtores de nossas histórias.

Para tornar perceptíveis os sentidos dos fragmentos geralmente desprezíveis e considerados irrelevantes quando se constroem certas narrativas, faz-se necessário percebê-los na complexidade dos processos sociais. Nesse sentido, os discursos construídos pelos "olhares nativos" - para utilizar uma expressão cara aos antropólogos - desvelam e testemunham as situações históricas vivenciadas nos diferentes contextos e momentos históricos das cidades do DF. O cotidiano da cidade também é tecido pela imprevisibilidade e pela invisibilidade e isto pressupõe afirmar que para além da visibilidade nas narrativas existentes e das evidências temporais e espaciais, na cidade estão presentes outros movimentos reveladores das marcas singulares e coletivas deixadas por diferentes sujeitos, seja pela capacidade de instaurar novas referências para a cidade, seja pelas resiliências e resistências que apontam novos enredamentos na trama social da cidade. Compreendemos que a construção de uma história local passa pela percepção instrumentalizada destes fragmentos que perpassam as cidades.

A história de Brasília, apesar de amplamente documentada por registros escritos e audiovisuais, será quase impossível lançar um novo olhar se o tipo de fonte utilizada se restringir à documentação produzida por uma ótica estritamente oficial, positivista. Reside neste aspecto a importância de se trabalhar com ocorrências policiais, seja na universidade ou mesmo em contextos escolares. 


\section{METODOLOGIA}

"No passado, podiam-se acusar os historiadores de querer conhecer somente as 'gestas dos reis'. Hoje, é claro, não é mais. Cada vez mais se interessam pelo que seus predecessores haviam ocultado, deixado de lado ou simplesmente ignorado. 'Quem construiu Tebas das sete portas?' - Perguntava o 'leitor operário' de Brecht. As fontes não nos contam nada daqueles pedreiros anônimos, mas a pergunta conserva todo seu peso".

Carlo Ginzburg, 1987, p. 15.

É inegável o quanto a disciplina História desenvolveu o tratamento dado às fontes documentais, e sem dúvida, ampliou o seu campo de interesses, através de novos temas, novas 'fontes' e principalmente práticas interdisciplinares. Porém, se o olhar do pesquisador continua restrito ao tipo de fonte tradicionalmente considerada válida, o enfoque sempre permanecerá o mesmo. Ainda mais nas questões relacionadas à gênero, posto que as mulheres, tornaram-se objeto e sujeito da história somente a partir da década de 1960, sendo as fontes ainda escassas e quando encontradas poucas organizadas, dificultando assim o trabalho daqueles que buscam reconstruir a atuação das mulheres.

No entendimento de Soihet (2012, p.364), no meio dessa infertilidade documental, a documentação oficial como a policial e judiciária revela-se material privilegiado na tarefa de fazer vir à tona a contribuição feminina no processo histórico e, mesmo que sejam buscadas informações em jornais, periódicos e escritos literários, a utilização a documentação policial e jurídica "revela-se fundamental para podermos nos aproximar do cotidiano de homens e mulheres das classes populares".

Em vista disso e diante da grande quantidade de fontes existentes sobre Brasília (na sua grande maioria oficiais) como ocorrências policiais, registros de óbitos, carteiras de trabalho de mulheres, e recortes de jornais - algumas das fontes que compõem a análise deste estudo; optou-se, pelo método qualitativo de pesquisa. 
Conforme José Luís Neves (1996) a pesquisa qualitativa envolve um conjunto de diferentes técnicas (métodos) interpretativas que visam descrever e decodificar os componentes de um sistema (às vezes muito complexo) de significados. Seu principal objetivo é traduzir e expressar o sentido dos fenômenos do mundo social; trata-se de reduzir a distância entre indicador e indicado, entre teoria e dados, entre contexto e ação. Logo, consiste num método que se assemelha a procedimentos de interpretação dos fenômenos do cotidiano, que passam despercebidos. Segundo o autor, a pesquisa qualitativa é constituída a partir de materiais que não receberam um tratamento analítico ou que podem ser reexaminados com vistas a uma interpretação complementar ou mesmo originais.

Os estudos baseados em documentos têm o propósito de extrair elementos de análise, organizando-os e interpretando-os segundo os objetivos da investigação proposta, em vista disso, é fundamental que os problemas de pesquisa estejam ao menos provisoriamente definidos ao se iniciar a pesquisa documental. Nesta pesquisa, o problema foi definido no projeto, mas os resultados só surgem durante a investigação das fontes, não sendo raro, que surjam outras problemáticas, mas isso vai depender do quão familiarizado estará o pesquisador com suas fontes.

Os documentos não falam por si só, é necessário que o historiador construa uma problemática que seja significativa para aquelas fontes, que faça indagações adequadas, entretanto, elas não respondem automaticamente às perguntas formuladas pelos pesquisadores. Trata-se inicialmente de um processo de investigação que orienta as categorias de análise e que exige determinados procedimentos: os documentos devem ser identificados, devem ser compreendidos como parte de um conjunto mais amplo de produções que fizeram sentido naquele momento (há de se evidenciar que contextualização é uma palavra-chave para a pesquisa histórica), devem receber um tratamento orientado pelo problema de pesquisa que o pesquisador traz, e por fim, deve-se estabelecer a montagem das peças como num quebra-cabeça, produzindo uma narrativa organizada e inteligível.

Nesse sentido, foi imprescindível para a orientação deste trabalho como um todo - não somente a pesquisa documental - a noção de paradigma indiciário, desenvolvida pelo historiador Carlo Ginzburg (1989). Este autor procura mostrar que assim como o médico (ou o detetive) produz seus diagnósticos observando, 
investigando os sintomas (ou indícios) e recolhendo dados, outros saberes indiciários produzem conhecimentos lendo e interpretando os sinais (pistas) e os indícios, partindo de aspectos que podem parecer irrelevantes em um primeiro momento. Como na pesquisa histórica, pois, o historiador é responsável pela decifração de um enigma pela elucidação de um enredo, buscando coisas insignificantes para revelar um grande segredo.

A pesquisa documental pode ser realizada em fontes muito diversas: tabelas estatísticas, cartas, pareceres, fotografias, atas, relatórios, obras originais de qualquer natureza - pintura, escultura, desenho, texto etc, notas, diários, projetos de lei, ofícios, discursos, mapas, testamentos, inventários, informativos, depoimentos orais e escritos, certidões, correspondência pessoal ou comercial, documentos informativos arquivados em repartições públicas, associações, igrejas, hospitais, sindicatos. Na concepção positivista de História o documento é algo objetivo, neutro, "prova" que serve para comprovar fatos e acontecimentos. A ideia do documento como monumento, que ganha força nas últimas décadas do século $\mathrm{XX}$, contrapõe-se a esta acepção, postulando que toda fonte histórica "exprime o poder da sociedade do passado sobre a memória e o futuro" (LE GOFF, 1996, p. 10). Como produto de uma sociedade, o documento manifesta o jogo de força dos que detêm o poder naquele contexto. Não são, portanto, produções neutras ou ingênuas. Traduzem leituras e modos de interpretação vividos por um determinado grupo de pessoas em um dado tempo e espaço. A pesquisa documental, como método de investigação da realidade social, pode ser utilizada tanto nas abordagens de natureza explicativa quanto naquelas de caráter compreensivo (com enfoque mais crítico). Todo este percurso está marcado pela concepção epistemológica a qual se filia o investigador.

Para nós, a escolha das fontes que comporiam tal panorama documental revelou a complexidade dessa opção diante de um universo que se apresenta amplo e diverso. Logo estivemos cientes de que qualquer escolha implicaria em omissões, reconhecendo de início a imperfeição e provisoriedade da seleção. Nesse sentido, a pesquisa consiste, invariavelmente, em seleção, e como atribuição do pesquisador cabe reconhecer e justificar suas escolhas.

Para alcançar os objetivos propostos, optamos por nos concentrar no Fundo NOVACAP do Arquivo Público do Distrito Federal-ArPDF, acervo que contém a 
documentação referente ao período da construção de Brasília. Os conjuntos principais de fontes a serem pesquisadas no acervo do ArPDF consiste em:

a) Ocorrências policiais: identificamos 11 (onze) livros-ata que registram ocorrências de diversos tipos de violências envolvendo mulheres entre os anos de 1957 e 1961.

b) Livros de óbitos: são 02 (dois) livros-ata que registram os óbitos ocorridos entre 1957 e 1960.

c) Carteiras de trabalho: são 06 (seis) caixas em que foram identificadas 40 (quarenta) carteiras de mulheres contratadas pela NOVACAP.

d) Recortes de jornais: identificamos 41 recortes de jornais.

Como mencionado, as fontes a serem utilizadas fazem parte do acervo histórico do Arquivo Público do DF. Esses documentos estão disponíveis em versão digitalizada, porém, (ainda) não estão disponibilizadas on line. O acervo do ArPDF é composto por material textual (registros funcionais e de despesas, livros de atas e ocorrências, decretos, recortes de jornais, dentre outros), plantas arquitetônicas, fotografias, filmes, folhetos, relatos orais, cartazes, periódicos e material bibliográfico; compondo um cenário de relevância sem igual para pesquisas sobre a história de Brasília e do Distrito Federal.

Nesta pesquisa, nos dedicamos ao mapeamento das fontes documentais. Primeiramente foi feita uma leitura compartilhada de bibliografia relativa ao tema: gênero e história das mulheres, e história do Distrito Federal. O objetivo principal dessa etapa foi situar os estudantes na discussão de gênero, bem como observar/associar essa discussão com o período analisado (final da década de 1959) e também as condições em que essas fontes foram produzidas. Além disso, foi de suma importância a leitura de referenciais que constituem uma historiografia sobre Brasília (como os autores mencionados neste trabalho), focando principalmente no recorte temporal selecionado, isto é, o período da construção da cidade.

Após a discussão teórica, foram realizadas cinco visitas ao ArPDF, a fim de realizar identificação e solicitação do material a ser tratado como fontes documentais. No início da pesquisa, o acesso ao material digitalizado no acervo do Arquivo Público se apresentava como uma preocupação, mas, acabou se tornando uma feliz surpresa que o acervo tenha sido rapidamente compartilhado e apresentado em um formato 
com ótima qualidade para a pesquisa, sendo fundamental para que a pesquisa corresse da melhor forma possível.

Para gerar os dados analisados, foi mapeado um primeiro conjunto de fontes documentais: as ocorrências policiais. Estas consistem no material mais relevante para a pesquisa realizada, sendo também aquele que contém o maior volume documental, sendo primordial, pelo fato de registrarem ocorrências de diversos tipos de violências envolvendo mulheres, sejam como vítimas - a grande maioria - ou como acusadas, lembrando que esse conjunto documental está inserido no locus temporal que vai de 1957 a 1961.

Para o mapeamento e, por conseguinte, a análise destas ocorrências, foi elaborado um quadro de análise documental (ver em anexo 1), onde buscamos inserir várias particularidades das ocorrências tais como: tópicos para a melhor identificação das fontes como número do livro, da página, palavras-chave; localidade da denúncia, data e principalmente o tipo de denúncia; para o caso de uma busca rápida, uma síntese da ocorrência e o tipo de envolvimento feminino, ou seja, vítima ou acusada; e também um espaço para fazer a transcrição literal da ocorrência, em outro, a solução/providencias. Além destes, há dois espaços destinados à classificação e observação, neste caso o trabalho é mais analítico, comparado a inserção de dados referente à queixa do documento.

A partir desse quadro, seguiu-se a etapa mais demorada, ou seja, o mapeamento e a transcrições das ocorrências, devido o volume documental dessa fonte, 11 livros, com uma média total de 4000 ocorrências. O quadro de análise foi (e ainda será) de grande importância para diminuir o tempo de análise das ocorrências e especialmente para o se fazer levantamento de dados quantitativos. Assim, depois de selecionadas as ocorrências, foram realizados trabalhos de levantamento de dados por meio de uma tabulação. Sendo as ocorrências agrupadas em dois grupos gerais (1. Violência em âmbito doméstico/familiar; 2. Violência nos espaços públicos) e também em subgrupos, para diferenciar os crimes enquadrados de acordos com leis vigentes. Assim sendo, para tipificar as ocorrências, foram estudados - e discutidos - o Código Penal brasileiro e a Lei Maria da Penha (№ 11.340, DE 7 DE AGOSTO DE 2006). Por fim, para exibir os resultados, foram criados gráficos referentes ao quantitativo de ocorrências, e seus respectivos grupos, subgrupos e tipificações. 
No final da pesquisa foram analisados os registros de óbitos desse período, sendo mapeados e selecionados em formato de imagem, os registros que envolviam mortes de mulheres. Para a partir desse levantamento serem averiguados: data, local e causa da morte e, o nome e endereço da vítima. Finalmente, os registros analisados são correlacionados com esse cenário de violência contra mulheres.

\section{RESULTADOS E DISCUSSÃO DOS RESULTADOS}

A pesquisa resultou em um mapeamento em que, do total de quase 4 mil ocorrências, foram identificadas 279 situações de crimes cometidos contra mulheres, constantes em 236 registros de ocorrências, sendo em sua maioria denúncias feitas pelas próprias vítimas. Um número bem maior apresenta mulheres na condição de envolvidas, seja como denunciantes de violências cometidas contra outras pessoas, seja quando listadas como testemunhas ou nos casos em que são acusadas de algum crime. A fim de qualificar essas formas de violência, foram utilizadas as tipificações estabelecidas pela Lei Maria da Penha (91 registros de violência em âmbito doméstico) e 145 registros de violências classificados de acordo com Código Penal (crimes contra a pessoa e a vida que não denominam especificamente a esfera familiar e doméstica).

Entre os 91 casos de violência doméstica predominam a violência física (42) e a violência psicológica (29), seguidas da violência patrimonial (13) e violência moral (07). Não houve registros de violência sexual em espaços privados. Dentre os demais crimes identificados, 145 registros de violências ocorridas em espaços públicos, predominam: lesão corporal (42); estupro/ tentativa de estupro (40) e assédio de tipo sexual (15), em que se destacam crianças como vítimas. A esses se somam os casos de roubos/furtos (13) e homicídio/ tentativa de homicídio (08). Em seguida, denúncias de injúria/calúnia/difamação (05), assédio moral/constrangimento ilegal (04), subtração de incapazes (06) e outros totalizam 52 ocorrências.

Realizamos uma tabulação a partir da qual podemos aferir um detalhamento dos dados a partir de dois referenciais: 1) a tipificação das violências denunciadas, totalizando 279 tipos de crimes listados e 2) por agrupamento de tipologias criminais conforme o número de registros, totalizando 236 ocorrências mapeadas. Dentre os 
dados do primeiro grupo temos, em relação às formas de violências cometidas em espaços públicos, destacamos algumas situações que nos parecem representativas em relação às representações sobre mulheres naquele contexto. Temos por exemplo, entre os 42 casos de lesão corporal o predomínio do uso de força física: socos, pontapés, estrangulamentos, ataque com ferramentas de trabalho e espancamentos diversos, cometidos por homens contra mulheres em vias públicas. Diversos casos registram a apreensão de armas brancas, como facas ou "peixeiras", no momento de revista dos acusados, além da identificação de armas de fogo em menor número. Entre as localidades destacam-se os espaços de sociabilidade da Cidade Livre (atual Núcleo Bandeirante): cinema, boates e bares, zona de prostituição (chamada Baixo Meretrício ou Placa da Mercês), mercados; os locais em que se concentram os serviços públicos da NOVACAP/Velhacap (atual Candangolândia), em especial as imediações do IAPI e os locais de moradia denominados como Invasões: Invasão do IAPI, Invasão da 4a Avenida, Morro do Urubu, Morro do Querosene, bem como a Vila Amaury. Entre as causas chama atenção a recusa das vítimas às investidas feitas pelos homens, sendo significativa a recorrente alegação de que os agressores se encontravam embriagados no momento de acometimento dos atos. Entre as vítimas se destacam tanto as prostitutas- identificadas como "mulheres da vida", quanto aquelas mulheres identificadas como "moças de família" no caso das solteiras ou "mulheres direitas" para designar as casadas; entretanto, há de ressaltar a disparidade nas providências tomadas pelas autoridades policiais.

Um outro conjunto de crimes que se destacam em espaços públicos são aqueles relacionados à violência sexual, totalizando 40 ocorrências entre estupros, tentativas de estupro e estupros de vulneráveis. A esses casos se associam outras formas de violência, em especial, agressões físicas de diversos tipos. Destacam-se os casos de violências praticadas por superiores hierárquicos, em especial contra jovens menores de 18 anos e que trabalham em estabelecimentos comerciais da Cidade Livre. A esse conjunto de casos, em comparação com os casos de lesão corporal, percebemos uma menor incidência da alegação de que os agressores estivessem embriagados. Já em relação às providências tomadas, destaca-se a "deportação como mau elemento" nos casos mais severos ou a "ameaça de deportação", entretanto, causa 
estarrecimento que de modo geral o desfecho das investigações assinale a concessão de liberdade aos acusados, sem explicações mais detalhadas. Destacam-se casos de denúncias contra soldados da Guarda Especial de Brasília- GEB. Alguns casos envolvem o "defloramento" de jovens sob a promessa de casamento e posterior abandono. A alguns desses casos a solução indicada é que seja providenciada a união matrimonial de agressor e vítima. Destaca-se a quantidade de crianças que sofrem tentativas de violência sexual ou estupros consumados. A estes número se somam as denúncias de assédio de tipo sexual, totalizando 15 ocorrências. Nesse caso, desperta atenção o destaque dados nos registros ao fato da mulher ser casada ou estar grávida, enfatizando a gravidade dos casos exclusivamente nessas condições, o que nos traz a percepção de susceptibilidade das mulheres que não estivessem nessas condições.

No caso das violências ocorridas em âmbito doméstico ou familiar, de um total de 91 tipos de ocorrências destacadas em 51 registros feitos por mulheres, destaca-se a violência física com 21 ocorrências. Dentre essas, destacam-se como agressores os companheiros (esposos, namorados ou amantes). Nesse caso, as tentativas são predominantemente de homicídio, com uso de armas de fogo ou armas brancas letais. A justificativa para a agressão passa pela desconfiança de traição, pela embriaguez que teria ocasionado "uma atitude impensada", ou pela "discussão acalorada entre o casal". Predominam os casos em que as mulheres vítimas são as próprias denunciantes, destacando-se nos registros o relato de recorrência das agressões e a solicitação de que a autoridade policial "converse" com o agressor para que não permaneçam as agressões. São significativos, entretanto, os casos em que os denunciantes são terceiros, em especial vizinhos que relatam não conseguirem mais conviver com as constantes agressões. A amenidade das providências nesse caso fica evidente, sendo o mais usual procedimento que o delegado de polícia "repreendesse severamente o acusado" e este fosse imediatamente posto em liberdade. No desfecho, os registros evidenciam o compromisso verbal do agressor de não mais agredir a esposa. A estes casos se somam aqueles em que se evidencia a associação entre violência física e psicológica, aqui mapeadas 15 ocorrências. Nessas se destacam em especial, as ameaças e agressões de ex-companheiros que não aceitam o fim do relacionamento. Ganha relevância o fato de que as ameaças sejam também 
direcionadas aos filhos, ou ao fato de que a mulher não conseguirá manter a subsistência desses, o que gera uma situação de insegurança e a sensação de impotência para as mulheres.

Acompanha o Relatório, um Anexo com as transcrições completas e os quadros de análise documental, a classificação por tipologia de violências denunciadas e os gráficos produzidos a partir da pesquisa, complementando as informações aqui listadas. Esse material complementar totaliza 228 páginas.

\section{CONSIDERAÇÕES FINAIS}

Há de se ressaltar que as denúncias de violências contra mulheres - naquele período bem como nos dias de hoje - se caracterizam por serem crimes subnotificados, visto que estão inscritos em uma cultura patriarcal e machista que desestimula, sobretudo, as denúncias de violências que ocorrem em âmbito doméstico e àquelas que se referem a crimes sexuais. Assim, interessou mais compreender os tipos de crimes cometidos e denunciados do que identificar um percentual representativo das violências às quais às mulheres estiveram expostas naquele momento. O mapeamento realizado corresponde a um importante instrumental para pesquisas futuras, apresentando de forma organizada fontes documentais que possibilitam o preenchimento de uma lacuna na historiografia do Distrito Federal. Seja pelo ineditismo do recorte dado às fontes documentais, seja pela relevância social do tema, acreditamos que a pesquisa realizada traz uma grande contribuição para a produção de pesquisas históricas que associem gênero e o contexto histórico da construção de Brasília. 


\section{REFERÊNCIAS}

ALMEIDA, Juniele; ROVAI, Marta (org.) Introdução à história pública. São Paulo: Letra e Voz, 2011.

BEAUVOIR, Simone. O segundo sexo: fatos e mitos. São Paulo: Difusão Européia do Livro, 1960.

BEÚ, Edson. Expresso Brasília: a história contada pelos candangos. Brasília: Ed. UnB, 2012.

BOURDIEU, Pierre. O poder simbólico. 3ạ ed. Rio de Janeiro: Bertrand Brasil, 2000.

GINZBURG, Carlo. Mitos, emblemas, sinais. São Paulo: Companhia das Letras, 1989.

- O queijo e os vermes: o cotidiano e as ideias de um moleiro perseguido pela inquisição. São Paulo: Companhia das Letras, 1987.

HOLSTON, James. A cidade modernista, uma critica de Brasília e sua utopia. São Paulo, Companhia das Letras, 1993.

- Cidadania Insurgente: disjunções da democracia e da modernidade no Brasil. São Paulo: Companhia das Letras, 2013.

LOURO, Guacira Lopes. Nas redes do conceito de gênero. In: LOPES, M. J. D.; MEYER, D. E.; WALDOW, V. R, (orgs.). Gênero e saúde. Porto Alegre, RS: Artes Médicas, 1996

MENDES, José. O desafio das identidades. In: SANTOS, Boventura de Sousa (org.). A Globalização e as Ciências Sociais. São Paulo: Cortez, 2002.

NEVES, José Luis. Pesquisa qualitativa - características, usos e possibilidades. Cadernos de pesquisa em administração, São Paulo, vol. 1, no 3, 2 Sem./1996.

MONTENEGRO, Antônio Torres. História oral: caminhos e descaminhos. In Revista Brasileira de História- Memória, História, Historiografia. São Paulo: ANPUH/Marco Zero. v.13, no25/26, 1993.

OLIVEIRA, Márcio de. Brasília: o mito na trajetória da nação. Brasília: Paralelo 15, 2005.

ORLANDI, Eni P. Análise de discurso: princípios e procedimentos. Campinas, SP: Pontes, 2005.

As formas do silêncio: no movimento de sentidos. Campinas: Ed. da

UNICAMP, 1992. 
PESAVENTO, Sandra Jatahy. História e História Cultural. Belo Horizonte: Autêntica, 2003.

PINSKY, Carla Bassanezi. Mulheres dos Anos Dourados. In: História das mulheres no Brasil/ DEL PRIORI, Mary (org.); PINSKY, Carla Bassanezi (Cord. De textos), 10. Ed. São Paulo: Contexto. 2012.

RIBEIRO, Gustavo Lins. O capital da esperança: a experiência dos trabalhadores na construção de Brasília. Brasília: Editora da UnB, 2008.

RICOEUR, Paul. Interpretações e Ideologias. Rio de Janeiro: Francisco Alves, 1983.

SCOTT, Joan. Gênero: uma categoria útil de análise histórica. (Trad. Christine Rufino Dabate e Maria Betânia Ávila). Recife: SOS Corpo, 1991. p.1-2.

SILVA, Joelma Rodrigues. Mulher: "pedra preciosa"; prostituição e relações de gênero em Brasília (1957-1961). Dissertação (Mestrado) - Universidade de Brasília. 1995.

SILVA, K.V. SILVA. M. H. Dicionário de conceitos históricos. 3.ed., São Paulo: Contexto, 2013.

SOIHET, Raquel. Mulheres Pobres e Violência no Brasil Urbano. In: História das mulheres no Brasil/ DEL PRIORI, Mary (org.); PINSKY, Carla Bassanezi (Cord. De textos), 10. Ed. São Paulo: Contexto. 2012.

; PEDRO, Joana Maria. A emergência da pesquisa da história das mulheres e das relações de gênero. Rev. Bras. Hist.[online]. 2007, vol.27, n.54, pp.284.

SOUSA, Nair Heloísa Bicalho. Construtores de Brasília. Petrópolis, Vozes, 1983/ Idem. Trabalhadores pobres e cidadania: a experiência da exclusão e da rebeldia na construção civil. Uberlândia: EDUFU, 2007.

SOUZA, Meriti. Mito fundador, narrativas e historia oficial: representações indentitárias na cultura brasileira. São Paulo: Universidade Estadual Paulista, 2004. 